\title{
Family projection methods: A review
}

\author{
Nico Keilman (nico.keilman@econ.uio.no)
}

19 March 2018

Prepared for inclusion in the Springer volume Analytical Family Demography edited by Robert Schoen.

\begin{abstract}
I review methods for projecting the family structure of a population into the future. The focus is on Western countries. I define the concept of "family", and stress the close link between family and household. There is an important distinction between family position (the attribute of individuals) and family type (the attribute of families). I propose a typology of family projection models, and review a large number of approaches. Consistency problems (being a generalization of the two-sex problem of demography) arise when interrelated events experienced by members of the same family are modelled. Little is known about the accuracy of various types of family projection models. The chapter concludes with an evaluation and assessment of various types of family projection models, using criteria such as data requirements, output detail, ease of programming, and extrapolation of parameters. Agent Based Models and probabilistic projection models are promising avenues for future work.

\section{Key words}

Family, projection, forecast, model, family type, family position, household, micro simulation, macro simulation, consistency, Agent Based Model
\end{abstract}




\section{Introduction}

Family projections are useful for the planning of welfare provisions, housing supply, and the demand for consumer durables. Elderly persons who live alone are more vulnerable than those who live with a partner. Therefore, family status is an important determinant of the need for formal and informal support and care for the elderly, in addition to health (e.g. Muller et al. 1999; Lakdawalla et al. 2003; Grundy and Jital 2007). Projections of social welfare spending depend, among other things, on the number of lone parents in the future (Jacobsen and Jensen 2014). Falling fertility rates and more frequent divorce and separation in Western countries after World War 2 have led to smaller families and households (OECD 2011); in turn, this has had a strong impact on housing needs (Van Vliet et al. 1985). Another consequence of smaller families has been an increasing demand for energy, because of economies of scale in households of different sizes (O’Neill and Chen 2002).

The aim of this chapter is to review projection methods for the family structure of a population. The focus will be on Western countries.

In what follows I frequently use the term "family and household model". This stresses the fact that every family forms a household, or is part of a household (cf. definitions below). Therefore, family projection models are often embedded in models that project households.

This review focuses on models, but discusses related conceptual and formal issues, too. First (Section 2), I define the concept of "family", and stress the close link between family and household. I introduce the important distinction between family position (of individuals) and family type (for families). Next (Section 3), I discuss family dynamics, both in terms of changes in family type and changes in family position. To model changes in family position is less complicated than modelling changes in family types. Section 4 contains a typology of family projection methods and models, and reviews a large number of approaches. One particular problem, namely how to model interrelated events experienced by members of the same family, is taken up in Section 5. This so-called consistency problem is a generalization of the well-known two-sex problem of demography. In Section 6, I argue that very little is known about the accuracy of various types of family projection models, when projection outcomes are compared with actual outcomes. Section 7 gives an evaluation and assessment of various types of family projection models, using criteria such as data requirements, output detail, ease of programming, and extrapolation of parameters. Conclusions in Section 8 mention research topics that should get more attention in the future.

\section{What is a family? Conceptual issues}

Durkheim's classic notion of a "nuclear family" refers to a married couple and their dependent children, living together but apart from other kin (Moen and Forest 1999; Hoffmann-Nowotny 1987; Smith 1968). During the post-World War II period, the notion of a family in Europe and the United States has broadened to include a range of forms. With marriage becoming less central in shaping lifecourse transitions, consensual unions became more widespread and, in some countries, heterosexual and homosexual registered partnerships received legal recognition. The increase in separation and divorce has led to new types of families and living arrangements.

These new forms of living arrangements have given rise to a number of questions around the notion of a family (Tillman and Nam 2008). For instance, should we consider a cohabiting or a same-sex couple 
as a family? Does the family definition also cover lone parents? When a lone mother starts to cohabit with a man, does she form a new family, even when the new partner does not legally adopt the children? Such issues are important when families are viewed from the perspective of the special rights and obligations family members have with each other (Lenoir 2007).

When definitions of the notions of family and family members differ between countries or over time, this will result in statistics on families that are not comparable. Population censuses are an important source of information about the family structure of a population, and hence the United Nations have put much effort in coordinating data collection about families in subsequent rounds of censuses. The most recent example is the extensive set of guidelines in the chapter on families and households in the "Recommendations for the 2020 Censuses of Population and Housing"; see UNECE (2015). The details of what constitutes a family (and how to define its members) are complicated, but here I shall mention three important aspects of the recommended family notions: (i) the link between household and family; (ii) the important distinction between family type and an individual's family position; and (iii) the definition of "child".

1. Paragraph 783 of the Census Recommendations mentioned above states that "A 'family nucleus' is defined in the narrow sense as two or more persons who live in the same household and who are related as marital, registered, or consensual union (that is, cohabiting) partners of either opposite or same sex, or as parent and child. Thus a family comprises a couple without children, a couple with one or more children, or a lone parent with one or more children." The members of such a family nucleus or "family" in short, cannot live in two or more separate households. This means that a family is just a particular type of household, in addition to other household types (for instance, a one-person household). In brief, a household consists of all related or unrelated persons who live in one dwelling (dwelling unit household definition). A further restriction may be that they share a household budget (housekeeping definition of a household). A detailed discussion of the household concept is beyond the scope of this chapter; the interested reader is referred to the Census Recommendations.

2. The family definition above implies that one may distinguish different types of families, such as a married couple with or without children, a lone parent family, a cohabiting couple (irrespective of sex) with or without children, a reconstituted family, etc. In contrast, one may consider the notion of family status or family position, that is, the position an individual person has in his or her family. Examples are spouse, child, and registered partner. Family position is an attribute of the individual, whereas family type is an attribute of the family (cf. Willekens 2010). It follows that a family of a certain type can include family members with different family positions (e.g. a lone parent family, which includes one or more children and a lone parent).

3. The Census Recommendations state that a 'child' refers to a blood, step-, or adopted son or daughter (regardless of age or marital status) who has usual residence in the household of at least one of the parents, and who has no partner or own child(ren) living in the same household. Grandsons and granddaughters of at least one grandparent who have usual residence in the household but where there are no parents present may also be included. Foster children should not be included.

The family definition in the Census Recommendations is much wider than that of Durkheim and others, who restricted themselves to a married couple and their own child(ren). However, even wider definitions have been used; see Hoffmann-Nowotny (1987) for a discussion. One example is a three- 
generation family, consisting of at least one grandparent, his or her son or daughter (with or without a partner), and at least one grandchild. The Census Recommendations do not consider this as one family, but as two: "A 'three-generation household' consists of two or more separate family nuclei or one family nucleus and (an)other family member(s), containing at least three generations. The youngest two generations should always constitute one family nucleus. For example, a woman who is living in a household with her own child(ren) and her own parent(s) should be regarded as being in the same family nucleus as the child(ren) even if she is never married. Her own parents would then constitute a second family nucleus within the same household." (UNECE 2015, p.165). An extremely wide family definition is that of Koschorke (mentioned by Hoffmann-Nowotny 1987): any group taking care of any offspring. In what follows I shall use the family definition as recommended by the UNECE, unless stated otherwise.

\section{Family dynamics}

The family structure of a population changes over time, caused by underlying processes of family formation and dissolution. When we are interested in projections for that structure in the future, the question is whether the projection model should be limited to compute the family structure at subsequent points in time (comparative statics). Alternatively, one may model family dynamics during subsequent time intervals as well, that is, processes of family formation and family dissolution. In the current context, the term "dynamics" reflects family events, such as marriage, or childbirth, or separation. In everyday language it would mean "change", or "motion".

A detailed classification of families by family type or of individuals by family status leads to a large amount of household change during a particular period. When we just distinguish between maritalcouple families and other families, a cohabiting mother whose partner leaves the household will not change family type. This would be the case as soon as cohabiting couples with children and lone parents are distinguished separately. Prinz et al. (1995) show how family projection results may differ when one proceeds from a simple model based on just three family positions (single; married; cohabiting) to a full family status model with six different positions (single and never-married; single and divorced; single and widowed; married; cohabiting and never-married; cohabiting and previously married) $)^{1}$.

\subsection{Longitudinal families}

An individual person is born, dies, and experiences during his life several events, such as home leaving, start of a partnership, marriage, childbearing etc. Events of this type reflect changes in individual family position. When the focus is on the changes in families of various types, one will be confronted with the problem of longitudinal families: when a family splits, it is often difficult to determine which part is the original family, and which part constitutes a new one. In other words, when can two families that exist at two points in time be considered as the same family (McMillan and Herriott 1985)? Imagine the following situation. A married couple with three children separates and the man leaves to start cohabiting with another woman who lived alone. The result is a lone mother and a cohabiting couple. Did these events lead to two truly new families? Alternatively, is the oneparent family a continuation of the old family (although of a different type)? In order to answer such questions, one has to formulate continuity rules. One possibility is to call a family a continuous one as long as 50 per cent or more of its members are the same at two points in time. In that case, the lone

\footnotetext{
${ }^{1}$ «Single» in the sense of «not living as a couple».
} 
mother and her three children would not form a new family. Another possibility is the rule that two families that have the same head are the same family. This may lead to the decision (depending on the definition of family head) that the man who now lives with a new partner in fact lives in the same family. The continuity rule chosen for a particular situation is often arbitrary, and an important objection is that different rules lead to different results (Citro 1985; McMillan and Herriott 1985).

To avoid problems associated with arbitrary continuity rules, scholars who wish to model family dynamics often take the individual rather than the family as the unit of analysis (Duncan and Hill 1985, 368-372; Van Imhoff and Keilman 1992; Murphy 1995, 163). In such an approach, individuals move between family positions. A change from one family position to another one is a family event for the individual. As an example, consider the following sequence: from «child with two parents» to «cohabiting» to «married» to «married, one child» to «separated» to «deceased». Changes of family type that occur within certain time intervals are not modelled explicitly. Rather, individuals with certain family positions are grouped and regrouped into families of various types at fixed points in time. In other words, a family changes because one or more of the members change family position.

\subsection{Interrelated events for members of the same family}

To focus on individuals rather than on families when analysing family dynamics circumvents the problem of longitudinal families, but it leads to another problem: many family events for members of the same family are interrelated. An event for one family member often induces an event for other members. When the last/only child of a lone parent leaves the household, the mother or father is no longer a lone parent. If we want to understand family dynamics at the individual level, we must take into account these and other links between events experienced by members in the same family. The complexity of these interrelationships depends on the level of detail in the classification of family positions for individuals. For instance, with only four marital states (never married, currently married, divorced, widow(er)) we just have to trace marriage and divorce for both partners, and death of one spouse together with transition to widowhood. But with a reasonable set of proper family positions (for instance: child with one parent, child with both parents, cohabiting with/without children, married with/without children, lone parent, other family position) there are many interrelationships of various types. To give one example: imagine that a lone father marries a lone mother. The adults change family position and marital status, and all children change family position. In Section 5, I discuss possible modelling approaches to handle interrelated events.

\subsection{Family expansion}

One specific case of family dynamics is family expansion caused by the birth of a child. Some models that I review in Section 4 keep track of the number of co-residing children in the family. This is clearly a variable of interest for social policy makers who design welfare policy for lone parents and their children, and for purposes of housing policy, when the interest is in family size. The number of coresident children in a family at a certain point in time is the net result of three processes: (i) birth of first, second, third ... children; (ii) survival of those children; (iii) leaving from and returning back to the parental home of those children. The first of these three, namely fertility by parity of the mother, has received much attention in demography. Parity progression is of central concern in the analysis of kinship networks; e.g. see Chapter 9 in this volume by Schoen. In the current chapter, I limit myself to co-residing kin. Li (Chapter 14 in this volume) discusses projections of the population broken down by parity irrespective of where they live. 
To keep track of the number of co-residing children poses a large challenge in dynamic multistate macro simulation models; see Sections 4.2.3 and 5. The reason, as mentioned earlier, is that the behaviour of children (home leaving) changes the status of their parents, when the number of coresiding children is one of the attributes of those parents.

\section{Models: a typology and brief review}

Many types of family projection models have been developed in the past. This section updates earlier literature reviews of family and household projection models, see Jiang and O'Neill (2004), Bell et al. (1995), and Arminger and Galler (1991). Another useful reference is Van Imhoff et al. (1995). Willekens $(2010,2015)$ reviews family and household demography in general, and discusses several of the projection models mentioned below.

We can classify models for family projection along several dimensions. One may distinguish between behavioural and descriptive models, between static and dynamic models, between macro and micro models, and between deterministic and stochastic models.

\subsection{Behavioural models}

Ideally, family forecasts are based on well-established theories of family behaviour. Many scholars have tried to develop social, economic and cultural theories to explain why families change over time. The reasons for such changes include: a reduced adherence to strict norms; less religiosity and an increase in individual freedom on ethical issues; female education, which has led to women having greater economic independence, and also facilitates divorce; more assertiveness in favour of symmetrical gender roles; the contribution of women to the labour market; increased economic aspirations; and residential autonomy (Lesthaeghe 1995; Van de Kaa 1987; Verdon 1998). In addition, there are also demographic factors, such as falling levels of fertility, and differences in longevity between men and women.

A number of behavioural models have been developed. Many focus on the search for, and the choice of a (marriage) partner. Examples include Choo and Siow (2006a, 2006b), Dagsvik et al. (2001), Henry (1972), Blossfeld and Timm (2003), Matthews and Garenne (2013a, b), Todd and Billari (2003), Todd et al. (2005), and Lee et al. (2008). Other behavioural models formalize the link between the housing market and the process of young adults who leave the parental home (e.g. Hooimeijer and Heida 1995) or the demographic effect of the labour market on women's childbearing behaviour (e.g. Nelissen 1995). Family instability (repeated changes in a child's family structure) and multipartner fertility (a parent's experience of having biological children with more than one partner) are two topics that have received much interest from scholars in the field of family demography (see Fomby and Osborne 2017 for an overview). However, these phenomena have not been included in formal models for the projection of various family types.

None of these theory-based formal models of family behaviour is general enough or has sufficient explanatory power that it can be used for forecasting. Two decades ago, Burch (1995) noted that methods for modelling family and household dynamics had made considerable progress, but that theory had lagged behind considerably. The situation is not much better today, which may reflect the complexity of the subject matter. Willekens (2018) argues forcefully that demographers ought to include theories of decision making in their models. In the current situation, as a second best to predicting families based on general behavioural theories, we look for regularities in the observed data, try to understand the trends, and extrapolate them into the future by means of formal time series 
models. Models based on this approach may be characterised as descriptive models. They do not include explicit behavioural relationships.

\subsection{Descriptive models}

Within the general class of descriptive models for family projection, it is customary to distinguish static models such as the headship rate model and the membership rate model on the one hand, and dynamic multistate models (also known as state space models) on the other. Dynamic family models deal explicitly with family events. A family event is defined as a change in family position that an individual experiences during a brief time interval; cf. Section 3. For instance, a person who lives as dependent child with his or her parents and starts to live with a cohabitee experiences the event of home leaving. While dynamic models explicitly project family events, static models do not.

\subsubsection{Headship rate models}

Headship rate models compute future numbers of families or households by combining an independent forecast of the population (broken down by age, sex, and often by marital status as well) with future values for the proportions of family or household heads in the population (specific of age, sex, etc.). By their nature, they can be typified as static models: they project numbers of families at future points in time (comparative statics), while processes of family and household change remain a black box.

Headship rate models have a long tradition in demography (US National Resources Planning Committee 1938; United Nations 1973; Keilman et al. 1988). Because of their modest data demands, they are used more frequently than the dynamic models to be discussed in Section 4.2 .3 (e.g. Jiang and O'Neill 2004). However, an important disadvantage is that they often provide little detail. Usually they are restricted to computing total numbers of families and households in future years. Other shortcomings are that the concept of family or household head is vague and varies between cultures, and that the approach ignores the link between changes in headship rates and the fundamental demographic events birth (and adoption), death, leaving parental home and migration.

\subsubsection{Membership rate models}

Membership rate models focus on the proportion of the population living in a family of a certain type, thereby avoiding the outdated concept of household head (Linke 1988). Similar to headship rate models, membership rate models combine an independent forecast of the population (broken down by age and sex) with future values for the population proportions living in families of various types (by age and sex). Wilson (2013) avoids the term "rate" and calls such models "propensity" models ${ }^{2}$. The family categories may be family size (Linke 1988) or some other typology, based on living arrangement (e.g. one-parent or two-parent family). A recent example is the random share model in Keilman (2017), which distinguishes the population by seven household positions. Four of these are family positions (child, living in consensual union, living in marital union, lone parent) and the remaining three are non-family positions (living alone, living in institution, other position). This model is described more fully in Section 4.4.

Akkerman (1980) describes a model that combines headship rates and membership rates. It starts from the simultaneous distribution of the population by age of household head and age of household member. The result is a square matrix with element $(i, j)$ reflecting the average number of household members in age $i$ per household whose head is aged $j$. This matrix provides the link between two vectors: (i) the population broken down by age, and (ii) households broken down by age of household.

\footnotetext{
${ }^{2}$ The term «rate» has a specific interpretation in demography, namely the number of events (births, deaths, marriages, migrations etc.) during a specific time interval in a certain population.
} 
Advantages and disadvantages of membership rate models are similar to those of headship rate models. They are relatively simple and they do not need very detailed input data. At the same time, being static by nature, they conceal processes of family formation and dissolution. An additional drawback is that when extrapolating historical membership rates, one has to ensure that the rates sum to one.

\subsubsection{Dynamic (multistate) models}

Dynamic family and household models were first developed in the 1980s, when existing multistate demographic models were applied to household analysis (Kuijsten and Vossen 1988). A prominent example of the group of dynamic models for family and household projection is the LIPRO ("LIfe style PROjections") model (Van Imhoff and Keilman 1991), which is based on the methodology of multistate demography but includes several extensions to solve the particular problems of family and household modelling, see https://www.nidi.nl/en/research/al/270101. LIPRO contains a very general algorithm to deal effectively with the problems that arise because the behaviour of various individuals who belong to the same family is interrelated (Section 3). In traditional demography, this is known as the two-sex problem. In LIPRO, the problem has been reformulated in a much more general manner as a so-called consistency problem (cf. Section 5). The solution in LIPRO can handle the relation between two or more adults, and that between children and parents, under processes of family formation and dissolution.

LIPRO is both a model and a computer program. The number of family or household positions (or "states" in general) and the interpretations of those states can be chosen freely: the program allows the "state space" to be defined in any form for which rates of transition between states can be estimated. Indeed, users have applied the program to a wide range of calculations in multistate demography. It has been used by Statistics Netherlands for their official household forecasts (Van Duin and Harmsen 2009) and by The Office of National Statistics for their marital status projections for England and Wales of 2006 (ONS 2009). Other applications of LIPRO include projections for Austria, Belgium, China, the European Union, Finland, Germany, Italy, Norway, Poland and Spain.

Two other dynamic models, which demand less detailed data, deserve to be mentioned: the family model developed by Prinz (1995), and the ProFamy model of Zeng et al. (1997, 1999, 2007). The designers of the latter model emphasize that it "requires only data that are available from conventional demographic data sources" (Zeng et al. 1999 p.62). Yet ProFamy's data requirements are relatively strong. To run the model, one needs birth and death rates broken down by age, parity, and marital status, rates for marital status transition (including entry into consensual union) by age and sex, and age-sex probabilities of leaving and returning to the parental home.

The advantage of dynamic models, as opposed to static models, is that they explicitly model family events. However, to model family dynamics for groups of persons may be complicated, in particular when the state space includes many different family positions. In that case, the model has to guarantee consistency of interrelated events; cf. Section 3.2. In section 5, I discuss possible solutions. A related disadvantage is that models of this type lead to heavy data needs.

\subsubsection{Hybrid models}

Some models combine aspects of a static and a dynamic approach to family modelling. De Beer (1995) gives an early example for the Netherlands. The projection model combines marital status dynamics (first marriage and remarriage, divorce, transition to widowhood based on four marital status positions) with a breakdown by six family and household positions (living with parents, living alone, living with partner, lone parent, other member of private household, living in institution). While this 
model was completely deterministic, it was the forerunner of the stochastic model for family and household projection described by Alders $(1999,2001)$ and De Beer and Alders (1999), see below.

\subsection{Micro and macro simulation models}

A further distinction is that between microsimulation models and macro simulation models. Macro simulation models start from groups of persons with certain characteristics (age, sex, family position, etc.) and apply rates for demographic events and family formation or dissolution to those groups. Linear algebra (vectors and matrices) is the mathematical tool for those models. The dynamic models mentioned in Section 4.2.3 are all examples of a macro simulation model.

Micro simulation models for the projection of households and families (Wachter 1987; Galler 1988; Nelissen 1994, 1995; Fredriksen 1998) take the individual as the unit of analysis, and attach a number of characteristics ("attributes") to each person: age, sex, survival status, number of children, family position, etc. All members of a certain family have the same unique identification number ("pointer"), which facilitates mapping family structures. The model updates the attributes (except for those that are fixed, such as date of birth or sex) for each individual by means of random draws from assumed probability distributions for events such as death, the birth of a(n additional) child, change in family position, etc. In this sense, the micro simulation model is a probabilistic model, but it only captures Poisson uncertainty. For a review, see Van Imhoff and Post (1998). A recent attempt to combine microsimulation and macro simulation has resulted in the MicMac model (Willekens 2009).

The advantage of microsimulation models is that they are very well suited to map complex relationships between variables. These include extended household, family, and kin structures (Jiang and O'Neill 2004), non-linear relationships between variables such as income and pension benefits (Nelissen 1994; Fredriksen 1998), as well as decision processes in relation to the search for a partner (e.g. Todd and Billari 2003, and Todd et al. 2005). Moreover, they can produce very detailed results. However, an important disadvantage of micro simulation models is that they require very detailed data. One needs micro data describing the attributes of all persons at a certain point in time, and changes therein. The latter data are needed to estimate the parameters in multivariate probability distributions for a correct representation of competing risks. Take the example of a family projection model that includes the following attributes (possibly more): sex, age, number of children, and marital status. Consider a married woman aged 30 years with one child. During a certain time interval, she is exposed to three competing risks: survival (while being married and having one child), birth of a second child (and remaining married), and marriage dissolution (while having one child). Micro simulation models frequently simulate events in a certain order, for instance survival first, then childbearing, followed by marital status change. Assuming such an ordering implies that one needs to simulate survival conditional upon no additional child and no change in marital status. Next, one needs to simulate childbearing conditional upon no change in marital status. This requires individual data on life courses of individuals that include the exact timing of these events. As an alternative, one can use aggregate data in the form of multiway frequency distributions - marginal distributions are not sufficient. ${ }^{3}$ Aggregate data of this kind are often unavailable. See also Galler (1995) for a discussion of

\footnotetext{
${ }^{3}$ This discussion assumes that the micro simulation model treats time as a discrete variable. Models in which time is a continuous variable simulate competing risk events by drawing the waiting time for the occurrence of each event, and selecting the event with shortest waiting time (e.g. Zinn 2012, 2017). However, since the model selects the event that came first, the other two events did not occur. Thus, the probability distributions from which waiting times are drawn have to be conditional distributions, and the same argument applies.
} 
competing risks and unobserved heterogeneity. He notes that one can randomize the sequence of events, instead of using a fixed order.

Multistate macro simulation models of the type discussed in Section 4.2.3 are based on the theory of continuous time Markov processes including competing risks, and empirical occurrence-exposure rates are used to estimate the model parameters (Hoem and Funck Jensen 1982; Alho and Spencer 2005). These models avoid the type of problems discussed above, but rest on other assumptions, for instance piecewise constant intensities, or the Markov assumption. The latter assumption can be rather strong, for instance in the case of migration, or of marriage dissolution.

Agent Based Models (ABM) take micro simulation one step further. ABM is a class of simulation models in which one views population change at the macro level as the outcome of decisions, actions and interactions at the micro level (Willekens et al., 2017; Willekens 2018). Decision processes per se cannot be observed, only their outcomes. The ABM approach involves microsimulation of a decision process (e.g. search for a partner), resulting in individual outcomes (marriage of a man and a woman of a certain age combination), and finally aggregation of these outcomes to the macro level (a two-way frequency table with marriages by age combination of groom and bride). One calibrates the parameters for the unobservable decision process such that the macro results agree with empirical aggregate data. Thus, compared to the models discussed earlier, the ABM-approach involves a shift away from events to processes and pathways, for example, from births to the decision to become a parent (Willekens et al. 2017). ABM-based family projections do not exist, to the best of my knowledge. However, the approach holds considerable promise, because the focus is on behavioural processes, in contrast to the mechanical extrapolative nature of descriptive projection models. Zinn $(2012,2017)$ and Todd et al. (2005) model partner search processes based on the ABM approach, but do not explicitly attempt to project the future. However, they supply useful building blocks for such projection models.

\subsection{Deterministic and probabilistic models}

Probabilistic forecast models are more appropriate for computing forecasts than deterministic forecast models. There are many possible future family developments for a given population, but some of these are more likely than others. As opposed to a deterministic forecast, which predicts only one number (or perhaps just a few, when projection variants are used) for a certain year, a probabilistic forecast tells us how likely it is that the number of families for a given year in the future will be within a certain range. Information of this kind allows policy makers, planners, and other forecast users in the fields of housing, energy, social security etc. to take appropriate decisions, because some family variables are more difficult to predict, and hence more uncertain than others. It also guides them once actual developments start to deviate from the most likely path. New actions or updated plans are unnecessary as long as developments are likely to remain close to the expected future. Deterministic forecasts traditionally deal with forecast uncertainty by formulating alternative scenarios, usually in terms of a high and a low trajectory for some key input parameter, in addition to a most likely trajectory (Jiang and O'Neill 2006). The drawback is that uncertainty is not quantified, and hence the user does not know how likely it is that the high trajectory will materialize, instead of the most likely trajectory. Moreover, the results are not plausible from a statistical point of view, as they implicitly assume perfect correlations across age, time, and type of family (Lee, 1999; Alho and Spencer 2005). De Beer and Alders were the first ones who introduced probabilistic family and household forecasts around the turn of the century; see Alders $(1999,2001)$ and De Beer and Alders (1999). Alders and De Beer used stochastic simulation and combined a probabilistic population forecast with forecasts of random shares. The shares distribute the population probabilistically over six family and household 
positions: individuals could live as a child with parents, live alone, live with a partner, live as a lone parent or in an institution, or belong to another category. Expected values for population variables and for the shares for specific household positions were obtained from observed time series, but the assumed statistical distributions of the shares were based on intuitive reasoning. The authors assumed perfect correlations across age and sex for the mortality rates, fertility rates and migration numbers in the stochastic population forecasts, as well as for the random shares. In other words, if a simulated death rate for a certain age was higher than expected, so were the rates for all other ages, and similarly for birth rates (by mother's age) and immigration numbers. In addition, the authors assumed perfect auto-correlation for the random shares: when the simulated shares for one particular year were high, they would also be high in the following years.

Scherbov and Ediev (2007) combined a probabilistic population forecast for the population disaggregated by age and sex with random headship rates (cf. Section 4.2.1), and applied their method to the case of Russia. Scherbov and Ediev based a large part of their uncertainty distributions on intuition. Wilson (2013) computed a probabilistic household forecast for Queensland. The model is a sequential propensity model (Section 4.2.). Household parameters were modelled as random walks. Due to the lack of past errors in estimates of living arrangements and households, standard deviations of the random errors were set based on judgement.

As noted, the uncertainty parameters (variances, covariances, correlations) of the family and household projection models discussed so far were largely judgemental. Alho and Keilman (2010) improved on this situation by estimating uncertainty parameters from data. Building on the random share method of De Beer and Alders, they projected Norwegian families and households of several types into the future. One important drawback of that work was that the uncertainty assessments were based on limited data, and that simplifying assumptions had to be made. Christiansen and Keilman (2013) used long time series data of observed shares for Denmark and Finland, and formal time series methods to quantify the uncertainty connected to family and household shares in the future. Expected values of the shares were computed using a multi-state model of family and household dynamics. Keilman (2017) simplified the latter model and applied time series methods to predict the random shares into the future, thereby avoiding the complexities of a multi-state model.

All probabilistic family and household projections discussed here are based on a frequentist approach. In this tradition, the probability of an event is linked to its relative frequency of occurrence. In contrast, in the Bayesian approach a probability is interpreted as a person's subjective belief. It is particularly useful when models rely on expert opinions, and when one combines this kind of information with data. The application of the Bayesian approach in demography, "Bayesian demography", started to gain popularity about ten years ago (Bijak and Bryant 2016). One important development is the work by the United Nations, assisted by statisticians from the University of Washington, to compute probabilistic demographic projections for all countries in the world by Bayesian methods (Raftery et al. 2012; Gerland et al. 2014; Sevcikova et al. 2016). The projections are probabilistic variants of the cohort component model, in which populations are broken down by age and sex. At present, Bayesian modelling has not been applied to family and household projection, but the method is well suited for that task. As noted above, it is able to include subjective information (e.g. beliefs about family composition in the future) with observed data, while the results come in the form of probability distributions for future values of the variables of interest. The three references to UNprojections above include a large number of statistical solutions to problems that will arise in Bayesian modelling of family dynamics. 


\section{The two-sex problem and consistency requirements}

The LIPRO model discussed in Section 4.2.3 is a macro model that projects groups of individuals broken down by age, sex, and family or household position, not families or households of certain types. The behaviours of men and women are modelled separately. This means that, for example, the number of women who marry during a period will not in general be the same as the number of men who marry during the same period according to the model. To solve this problem, LIPRO employs a consistency algorithm (Van Imhoff 1992). In this case, the consistency algorithm ascertains that equal numbers of men and women marry or enter cohabiting unions in each projection interval. The same applies to the numbers of men and women experiencing the dissolution of marital and cohabiting unions. Initially inconsistent numbers are reconciled by taking some form of average. Early applications of this approach involved the harmonic mean (Van Imhoff 1992). This means that when there is a discrepancy between the modelled numbers of men and of women experiencing one of these events, the numbers are adjusted to the harmonic mean of the inconsistent numbers of men and women. Next, corresponding transition rates are adjusted upwards (for the smaller number of events) or downwards (for the larger number of events).

The consistency algorithm described above assumes that each new couple consists of one male and one female partner. Some countries accept same sex partnerships (see Christiansen and Keilman 2013 for examples from Denmark and Finland). However, the numbers involved are often small enough to be ignored. Another aspect that is not included for practical reasons is marriage across international borders. Empirical applications require a well-defined population in time and space. In reality, some marriages take place between partners who live in two different countries, and the consistency requirement is not completely correct. Finally, it will be clear that polygamy cannot occur when consistency constraints are formulated.

The consistency problem discussed here is a more general case of the so-called two-sex problem of demography. ${ }^{4}$ The core of the problem is a correct representation of the formation of couples. In the context of marriage, it involves the search for an appropriate expression ("marriage model") for the combined exposure times of unmarried men and unmarried women. Weighted and unweighted averages of various types have been suggested for sex-specific exposure times, such as arithmetic, geometric, and harmonic averages (e.g. Keyfitz 1971, Schoen 1981, 1988). Recently, Alho (2015) formulated an overall two-sex marriage intensity as the average of the intensities for male and female marriages. At the same time, sex-specific exposure times were averaged. Thus, given an overall twosex intensity and a value of the two-sex exposure time, the product of the two predicts a certain number of marriages, which is the predicted numbers of marriages for men and for women. A notable feature of Alho's model is that it is based on a very general class of averages, including harmonic, geometric, and weighted arithmetic averages. Note that this approach differs from LIPRO's consistency algorithm. The latter algorithm reconciles inconsistent numbers of events, while Schoen (1981) and Alho (2015) compute averaged exposure times.

\footnotetext{
${ }^{4}$ The two-sex problem has a long history - it started in the context of fertility studies. Kuczynski (1932) was probably the first one who defined and computed net reproduction rates for both men and women, reflecting the average number of daughters (sons) born to women (men). Empirical values of these two reproduction rates are bound to be different. Hence, when taken to stability, male and female populations will grow or diminish at different rates and one sex will eventually dominate the other, which is unrealistic. Pollard (1975) and Schoen (1988) review the two-sex problem of demography.
} 
When designing a realistic model for couple formation (marriage, starting a consensual union) important aspects are competition and substitution. With competition, I mean that men of different ages compete to marry a woman of a certain age, and vice versa; some authors use the term "spillover effect", see Matthews and Garenne (2013) and Alho (2015). Substitution (or relative competition) implies that competition is weak when the competing men (or the competing women) have very different ages. Unmarried men aged 28 are less relevant for a man aged 23 who wants to marry, than 24-year old men are. In all of the literature on the two-sex problem, an important challenge has been to develop a marriage model that captures the competition and substitution effects correctly. One example is the model proposed by Pollard (1975), which computes the two-sex exposure time for men aged $x$ and women aged $y$ as a generalized harmonic mean of exposure times of unmarried men and unmarried women of all ages. Keilman (1998) applied Pollard's model to data for Norway for the years 1983-1992, and found that the competition effect was very small. Ekamper and Keilman (1993) demonstrated similar small competition effects for the Netherlands 1980-1984. Such effects are stronger when there are many more men than women in marriageable ages, cf. the case of China (Tuljapurkar et al. 1995). The model proposed by Alho (2015) is another example of a model with proper competition effects.

Descriptive models of family formation, both of the macro simulation and the micro simulation type, are confronted with the two-sex problem of union formation. However, for family dissolution, the situation is different. In multistate macro simulation models, the individual is the unit of analysis and modelling, and the model does not track couples. Hence, models of this type apply a dissolution rate for men to cohabiting or married men, and a dissolution rate for women to cohabiting or married women. The predicted numbers of men and women who dissolve the couple relationship will be inconsistent, and one needs a consistency algorithm to reconcile those inconsistent numbers.

Consistency problems of this type do not occur in a micro simulation model. The model keeps track of couples, and it applies a dissolution rate to the couple, not to the individual man or woman, to simulate separation or divorce.

Home leaving of young adults is another prominent example in which one is confronted with the consistency problem in a macro model but not in a micro model. For instance, in one LIPRO application (Keilman and Brunborg 1995), parents are distinguished according to the number of coresident children (one, two, three or more). A similar distinction is included in ProFamy (Zeng et al. 1997, 1999). Neither LIPRO nor ProFamy has the possibility to link parents in a given age group to children of a certain age. Indeed, the models compute numbers of young adults who leave (or return to) the family independently of numbers of parents who experience a change in the number of coresiding children. These numbers are different initially, and the model's consistency algorithm adjusts them so that they are the same. In a micro simulation model such consistency problems do not arise, because all family members are linked to each other through pointers. In such a model, it is simple to update the attributes of the parent when a child leaves the family.

Finally, note that consistency requirements are not necessary in a multistate macro simulation model in which individuals are distinguished by family size, rather than family position.

\section{Accuracy of family projections}

The users of a family projection have the right to know whether they can expect large or small errors in the projection. At the very least, we have to inform the user about the accuracy of historical projections, compared with observed trends. Whereas there is an abundance of accuracy assessments 
of population forecasts (see, for instance, NRC 2000), few studies of observed errors in historical family and household forecasts are available. It is reasonable to assume that in a specific setting, errors in a family projection will be larger than population projection errors, because the numbers involved are smaller.

One example of an evaluation of the accuracy of a family and household projection is the analysis of Alho and Keilman (2010) for the case of Norway. The authors evaluated predictions of age-specific shares of men and women in six family and household positions (child, cohabiting, living with marital spouse, living alone, living as lone parent, other household position) in 1997, 2001, and 2002 against empirical shares from survey and census data. The predictions stem from a multistate macro simulation of families and households (Keilman and Brunborg 1995) with the year 1990 as starting point. The evaluation showed that the forecast had predicted too few young cohabitants and young adults living alone, and to too many children living with their parents. There was evidence that prediction errors increase over time, as could be expected. Errors in shares of cohabiting or married men and women were small, compared to shares for other household positions. Error patterns for men and women were quite similar.

Table 1. Observed ${ }^{1}$ and projected ${ }^{2}$ numbers of families and households, Norway

\begin{tabular}{|c|c|c|c|c|c|}
\hline \multirow[b]{2}{*}{ Year } & \multicolumn{4}{|c|}{ Type of household } & \multirow[b]{2}{*}{$\begin{array}{c}\text { Average } \\
\text { household } \\
\text { size }\end{array}$} \\
\hline & One person & Couple & Lone parent & $\begin{array}{l}\text { All (including } \\
\text { other private } \\
\text { households) }\end{array}$ & \\
\hline & \multicolumn{5}{|c|}{ Observed numbers $(1000 \mathrm{~s})^{1}$} \\
\hline 2005 & 767 & 1118 & 116 & 2011 & 2.3 \\
\hline 2010 & 863 & 1173 & 123 & 2171 & 2.2 \\
\hline \multirow[t]{3}{*}{2015} & 878 & 1308 & 114 & 2317 & 2.2 \\
\hline & & & & & \\
\hline & \multicolumn{5}{|c|}{ Projected numbers (1000s), Basic Scenario ${ }^{2}$} \\
\hline 2005 & 967 & 970 & 177 & 2185 & 2.1 \\
\hline 2010 & 1048 & 972 & 193 & 2281 & 2.0 \\
\hline \multirow[t]{3}{*}{2015} & 1139 & 975 & 200 & 2387 & 2.0 \\
\hline & & & & & \\
\hline & \multicolumn{5}{|c|}{ Projection errors (\%), Basic Scenario } \\
\hline 2005 & 26.1 & -13.3 & 52.8 & 8.7 & -8.0 \\
\hline 2010 & 21.4 & -17.1 & 57.2 & 5.1 & -8.0 \\
\hline \multirow[t]{3}{*}{2015} & 29.7 & -25.4 & 75.2 & 3.0 & -9.5 \\
\hline & & & & & \\
\hline & \multicolumn{5}{|c|}{ Projected numbers (1000s), High Cohabitation Scenario ${ }^{2}$} \\
\hline 2005 & 830 & 1100 & 173 & 2147 & 2.1 \\
\hline 2010 & 891 & 1109 & 186 & 2235 & 2.1 \\
\hline \multirow[t]{2}{*}{2015} & 962 & 1132 & 193 & 2332 & 2.0 \\
\hline & \multicolumn{5}{|c|}{ Projection errors (\%), High Cohabitation Scenario } \\
\hline 2005 & 8.2 & -1.6 & 49.3 & 6.8 & -6.4 \\
\hline 2010 & 3.3 & -5.5 & 51.5 & 3.0 & -6.1 \\
\hline 2015 & 9.6 & -13.4 & 69.0 & 0.7 & -7.3 \\
\hline
\end{tabular}

Sources: 1. Statistics Norway. 2. 1990-based household projections by Keilman and Brunborg (1995). 
Table 1 shows projection errors after 15-25 years in predicted families and households of various types in the Norwegian projections of Keilman and Brunborg. Projected numbers for the years 2005, 2010, and 2015 are compared with empirical data from the household register of Statistics Norway. The projections included several projection variants. One was the so-called Basic Scenario, in which transition probabilities between family and household positions were estimated from data for the mid1980s; these parameters were kept constant during the whole projection period 1990-2020, except for changes caused by fertility, mortality and international migration. The latter parameters were borrowed from Statistics Norway's 1993-based official population projection. Projection errors are defined as projected minus observed number, as a percentage of the observed number. The table shows that households consisting of a married or cohabiting couple (with or without children) were severely under-predicted - projected numbers were up to 25 per cent too low after 25 years. On the other hand, one-person households were over-predicted by up to 30 per cent. Percentage errors in the total number of private households are much smaller, and decrease over time. This is counterintuitive, but the explanation is that the official population projections under-predicted immigration levels and gains in life expectancy between 1993 and 2015. Indeed, percentage errors in average household size tend to increase over time. Lone parent families are difficult to project accurately.

Table 1 gives also findings for a scenario in which entry rates into a consensual union of childless men and women were doubled, compared to the Basic Scenario. Projection errors for married and cohabiting couples and for one-person households for this High Cohabitation Scenario are much smaller than those in the Basic Scenario. Starting a consensual union in Norway was less popular in the mid-1980s than in later years.

If anything, this analysis of the accuracy of just one set of family and household projections shows that projection errors for couples and one-person households can be limited to about ten percent or less even after 25 years, if projection parameters are chosen carefully. For families that are less important numerically, for instance one-parent families, projection errors can be one order of magnitude larger. More work in this direction is required before we can state general conclusions. It will be very fruitful to compare family and household projection models in very different situations.

The projection evaluations discussed so far concern deterministic projections. For a certain variable in the future there is just one projected value (or more than one in case several projection variants were computed), and a comparison with the observed value ex-post gives the projection error. Signed errors (or their average or median values) indicate the bias in the family projection: was there a tendency for the projection being too high, or too low? Absolute or squared errors reflect projection accuracy: how far off? The situation becomes more complicated when we want to evaluate a probabilistic family projection (Section 4.4). Such projections take the form of a predictive probability distribution over future quantities of interest, and one compares this distribution with an empirically observed value. Statisticians have developed the tools to evaluate such predictive distributions; see Gneiting and Katzfuss (2014) for an overview. An important notion in this context is the so-called scoring rule, which assigns a numerical score $\mathrm{S}(F, y)$ to each pair $(F, y)$, where $F$ is the probabilistic forecast in terms of a predictive distribution, and $y$ is the realized value. Scoring rules have been developed both for analytical and simulated predictive distributions.

While empirical assessments of deterministic family projections are few, I do not know of any evaluations of probabilistic projections. 


\section{Evaluation of family projection models}

In this section, I compare the family projection models introduced in Section 4 according to five criteria: (i) data requirements, (ii) output detail, (iii) software, (iv) extrapolation of parameters, and (v) forecast accuracy. See Table 2. I do not consider other aspects, such as ease of training and use of the model, ease of updating, and possibilities for extending the model to sub-national projections (but see Bell et al. 1995 for such considerations).

Note that behavioural models are not included in Table 2 . Although some family projection models contain behavioural building blocks, most notably for the matching of two partners who form a couple, a purely behavioural family projection model (or even a predominantly behavioural model) does not exist at present, to the best of my knowledge. Note also that the model typology in Table 2 is not mutually exclusive. Some models belong to two or more types. For instance, the random share models constructed by De Beer, Alders, Wilson, Scherbov, Ediev, Christiansen, and Keilman (cf. Section 4.4) are all probabilistic models. At the same time they are of the headship rate type (Scherbov and Ediev), membership rate type (Alho and Keilman, Wilson), or the multistate type (Christiansen and Keilman). Descriptive micro simulation models may be of the multistate type, but applied to individual persons. One example is the demographic module in Nelissen's NEDYMAS model (Nelissen 1994).

Data requirements are largest for microsimulation models and probabilistic models. Microsimulation of family structures requires micro data for individual persons, both for the family situation at one point in time (from a census, a cross-sectional survey, or a register) and for changes therein during a certain time interval (from a panel survey or a retrospective survey, from a register, or from linked censuses). Probabilistic models require much data in order to estimate uncertainty parameters, such as correlations across ages, between men and women, between family positions, and across time.

Table 2. Evaluation of family projection models

\begin{tabular}{|l|l|l|l|l|l|}
\hline & \multicolumn{5}{|c|}{ Evaluation criterion } \\
\hline & $\begin{array}{l}\text { Data } \\
\text { requirements }\end{array}$ & Output detail & Software & $\begin{array}{l}\text { Parameter } \\
\text { extrapolation }\end{array}$ & $\begin{array}{l}\text { Forecast } \\
\text { accuracy }\end{array}$ \\
\hline Type of model: & \multicolumn{5}{|l|}{} \\
\hline Headship rate & Low & Very limited & $\begin{array}{l}\text { Easy to } \\
\text { design }\end{array}$ & Few & Moderate \\
\hline $\begin{array}{l}\text { Membership } \\
\text { rate }\end{array}$ & Rather low & Limited & $\begin{array}{l}\text { Moderately } \\
\text { easy to design }\end{array}$ & Several & Moderate \\
\hline Multistate & High & Good & Available & Numerous & $\begin{array}{l}\text { Potentially } \\
\text { good }\end{array}$ \\
\hline Hybrid & Moderate & Moderate & $\begin{array}{l}\text { Adapt } \\
\text { multistate } \\
\text { software }\end{array}$ & Many & $\begin{array}{l}\text { Potentially } \\
\text { good }\end{array}$ \\
\hline Microsimulation & Very high & Large & Problematic & Numerous & $\begin{array}{l}\text { Potentially } \\
\text { good }\end{array}$ \\
\hline Probabilistic & Very high & Large & Difficult & Numerous & $\begin{array}{l}\text { Potentially } \\
\text { good }\end{array}$ \\
\hline
\end{tabular}

Microsimulation models and probabilistic models produce very rich output. Take the example of a microsimulation projection model that includes age, sex, family type and number of children. One can 
use the model to produce a table with, say, the number of marital couples in 2030 who started to cohabit in 2020, who got one child in 2023, married in 2025, and who got another child in 2027. Detailed results of this kind are impossible to extract from macro models. Probabilistic models produce very rich output in the form of predictive distributions and forecast intervals for its output variables.

Headshiprate models for the projection of families and households are easy to program. A simple spreadsheet will be sufficient, provided that a projection of the future population broken down by age and sex (possibly by marital status as well) is available. On the other hand, user-friendly software for micro simulation programs is difficult to write. Each application seems to require its own specific computer program. An exception is the microsimulation part of MicMac, which is flexible and freely available, see https://www.nidi.nl/en/research/al/micmac/software. General purpose and user-friendly software for probabilistic family projection models does not exist. A marriage of existing packages for probabilistic population projection (e.g. PEP - Program for Error Propagation, see Alho and Spencer 2005) and deterministic multistate models (e.g. LIPRO) should be high on the research agenda.

All descriptive models contain parameters that need to be extrapolated. This is the key issue in any projection, i.e. what future trends are likely to be. The challenge is large when there are many parameters, which is the case for multistate models, microsimulation models and probabilistic models. Time series methods are frequently used, if empirical parameter estimates are available for several years. The crucial issue here is whether the trend observed in a certain parameter is representative for the future. Another problem is the extrapolation of a complete age schedule of transition rates (for instance death rates for married women). Should one extrapolate period age schedules or cohort age schedules? From a theoretic point of view, a cohort approach is better than a period approach, because people belong to only one birth cohort, and they do not live their lives in just one calendar year. However, the available data often implies that one cannot do better than extrapolating period schedules.

When the extrapolations are accurate, then also the projection results are accurate (provided the descriptive model is correct). The scores in the last column have little empirical basis, but are largely based on subjective belief and intuition. Headship rate models contain only a few parameters, and processes of family formation and dissolution remain a black box. Models of this type provide much less insight in family dynamics than multistate models do. For that reason it is likely that they produce less accurate projections.

\section{Conclusions}

In this chapter, I have given a broad and non-technical overview of models and methods developed by social scientists in the past to project future numbers of families. They range from extremely simple (e.g. headship rate models) to quite complicated (e.g. micro simulation models of the multi state type including algorithms for matching men and women who form a couple). Some of the models are static models, in the sense that they focus on changes in family structures at subsequent points in time. Underlying processes of family formation and family dissolution are not modelled explicitly. Dynamic models focus on the events that underlie family changes. They allow the modeller to link demographic processes such as birth, death, and migration to changes in family structure. Many of the family projection models currently in use in Western countries are of the dynamic type, stimulated by the availability of more detailed data from population censuses and longitudinal surveys. 
This review has identified a major shortcoming of most family projection models, namely the lack of theoretical underpinning. Behavioural theories about family formation and dissolution tend to be valid under very specific conditions, or have insufficient explanatory power to be used for forecasting purposes. Theories for the choice of a partner are an exception, and models of matching behaviour may fruitfully be included in family projection models. In Section 4.3, I discussed one approach that is particularly promising, namely Agent Based Models, which combine micro with macro simulation. The focus should be on theories of decision making.

A second line of research that deserves more attention is the development of methods for probabilistic family projection, starting from a Bayesian perspective. This approach integrates information from empirical data with expert opinion in a consistent statistical framework. The result is a probabilistic projection of family variables in the form of prediction intervals. Such intervals do not necessarily imply that the projections are more accurate than deterministic ones. However, they tell us how likely it is that the number of families for a given year in the future will be within a certain range.

Information of this kind allows the user to take appropriate decisions, because some family variables are more difficult to predict, and hence more uncertain than others. It also guides the user once actual developments start to deviate from the most likely path. New actions or updated plans are unnecessary as long as developments are likely to remain close to the expected future. 


\section{References}

Akkerman, A. (1980). On the relationship between household composition and population age distribution. Population Studies 34(3), 525-534.

Alders, M. (1999). Stochastische huishoudensprognose 1998-2050 ("Stochastic household forecast 1998-2050”). Maandstatistiek van de Bevolking 11, 25-34.

Alders, M. (2001). Huishoudensprognose 2000-2050: Veronderstellingen over onzekerheidsmarges ("Household forecast 2000-2050: Assumptions on uncertainty intervals"). Maandstatistiek van de Bevolking 8, 14-17.

Alho, J. (2015). Modeling incidence of nuptiality. Sociological Methodology 2015, 1-39.

Alho, J.M., Spencer, B. (2005). Statistical demography and forecasting. New York: Springer.

Alho, J., Keilman, N. (2010) On future household structure. Journal of the Royal Statistical Society Series A 173(1), 117-143.

Arminger, G. Galler, H. (1991). Demografische relevante Modellrechnungen: Simulations- und Analyseverfahren auf der Basis empirischer Erhebungen. Materialien zur Bevölkerungswissenschaft Heft 72. Wiesbaden: Bundesinstitut für Bevölkerungsforschung.

Bell, M., Cooper, J., Les, M. (1995). Household and family models: A review. Canberra: Commonwealth Department of Housing and Regional Development.

Bijak, J., Bryant, J. (2016). Bayesian demography 250 years after Bayes. Population Studies 70(1), 119.

Blossfeld, H.-P., Timm, A. (2003). Educational systems as marriage markets in modern societies: a conceptual framework. In: H.P. Blossfeld, A. Timm (Eds.) Who marries whom? Educational systems as marriage markets in modern societies (pp. 1-18). Dordrecht: Kluwer Academic Publishers.

Burch, T. (1995). Theories of household formation: progress and challenges. In: E. van Imhoff, A. Kuijsten, P. Hooimeijer, L. van Wissen (Eds.), Household demography and household modelling (pp. 85-108). New York: Plenum Press.

Choo, E., Siow, A. (2006a). Estimating a marriage matching model with spillover effects.

Demography 43:463-90.

Choo, E., Siow, A. (2006b). Who marries whom and why. Journal of Political Economy 114:175-201.

Christiansen, S., Keilman, N. (2013). Probabilistic household forecasts based on register data - the case of Denmark and Finland. Demographic Research 28, 1263-1302.

Dagsvik, J., Brunborg H., Flaatten A. (2001). A behavioral two-sex marriage model. Mathematical Population Studies 9:97-121.

De Beer, J. (1995). National household forecasts for the Netherlands. In: E. van Imhoff, A. Kuijsten, P. Hooimeijer, L. van Wissen (Eds.), Household Demography and Household Modeling (pp. 251270). New York: Plenum Press. 
De Beer, J., Alders, M. (1999). Probabilistic population and household forecasts for the Netherlands. Joint Economic Commission for Europe-EUROSTAT Work Session on Demographic Projections, Perugia, 3-7 May (Working paper 45).

Ekamper, P., Keilman, N. (1993). Sensitivity analysis in a multidimensional demographic projection model with a two-sex algorithm. Mathematical Population Studies 4(1), 21-36.

Fomby, P., Osborne, C. (2017). Family instability, multipartner fertility, and behavior in middle childhood. Journal of Marriage and Family 79(1):75-93.

Fredriksen, D. (1998). Projections of population, education, labour supply and public pension benefits: Analyses with the dynamic microsimulation model MOSART. Oslo: Statistics Norway (Social and Economic Studies 101).

Gerland, P., Raftery, A., Ševčíková, H., Li, N., Gu, D., Spoorenberg, T., Alkema, L., Fosdick, B., Chunn, J., Lalic, N., Bay, G., Buettner, T., Heilig, G., Wilmoth, J. (2014). World population stabilization unlikely this century. Science 346: 234-237.

Gneiting, T., Katzfuss, M. (2014). Probabilistic Forecasting. Annual Review of Statistics and Its Applications 1: 125-51.

Grundy, E., Jital, M. (2007). Socio-demographic variations in moves to institutional care 1991-2001: A record linkage study from England and Wales. Age and Ageing 36(4), 424-430.

Henry, L. (1972). Démographie: Analyse et modèles. Paris: Larousse.

Hoem, J., Funck Jensen, U. (1982). Multistate life table methodology: A probabilist critique. In: K.C. Land, A. Rogers (Eds.), Multiregional mathematical demography (pp. 155-264). New York: Academic Press.

Hoffmann-Nowotny, H.J. (1987). The future of the family. In: Plenaries of the European Population Conference (pp. 113-200). Helsinki: IUSSP/Central Statistical Office of Finland.

Jacobsen, R. H., Jensen, S. E. H. (2014). Future changes in age and household patterns: Some implications for public finances. International Journal of Forecasting 30(4), 1110-1119.

Jiang, L., O’Neill, B. (2004). Toward a new model for probabilistic household forecasts. International Statistical Review 72: 51-64.

Keilman (1998). Female dominance. In: Kuijsten, A., De Gans, H., De Feijter, H. (Eds.), The joy of demography ... and other disciplines: Essays in honour of Dirk van de Kaa (pp. 215-228). Amsterdam: Thela Thesis Publ.

Keilman, N. (2017). A combined Brass-Random Walk approach to probabilistic household forecasting: Denmark, Finland, and the Netherlands 2011-2041. Journal of Population Research 34: $17-43$.

Keilman, N. Brunborg, H. (1995). Household projections for Norway 1990-2020. Report 95/21. Oslo: Statistics Norway.

Keilman, N., Kuijsten, A., Vossen, A. (1988). Modelling household formation and dissolution. Oxford: Clarendon Press. 
Keyfitz, N. (1971). The mathematics of sex and marriage. Proceedings of the Sixth Berkeley Symposium on Mathematical Statistics and Probability, Vol. 4, 89-108.

Kuczynski, R. (1932). Fertility and reproduction: Methods of measuring the balance of births and deaths. New York: Falcon Press.

Lakdawalla, D., Goldman, D. P., Bhattacharya, J., Hurd, M., Joyce, G., Panis, C. (2003). Forecasting the nursing home population. Medical Care 41(1), 8-20.

Lee, R. (1999). Probabilistic approaches to population forecasting. Population and Development Review 24(supplement): 156-190.

Lee, A., Engen S., Sæther B.-E. (2008).Understanding mating systems: A mathematical model of the pair formation process. Theoretical Population Biology 73:112-24.

Lenoir R. (2007). The family as a social institution: Struggles over legitimate representations of reality. In: J. Houtsonen, A. Antikainen (Eds.), Symbolic Power in Cultural Contexts: Uncovering Social Reality (pp. 31-41). Rotterdam: Sense Publishers.

Lesthaeghe, R. (1995). The second demographic transition in Western countries: An interpretation. In K.O. Mason, A.-M. Jensen (Eds.), Gender and family change in industrialized countries (pp. 17-62). Oxford: Clarendon Press.

Linke, W. (1988). The headship rate approach in modelling households: The case of the Federal Republic of Germany. In: N. Keilman, A. Kuijsten, A. Vossen (Eds.), Modelling household formation and dissolution (pp. 108 - 122). Oxford: Clarendon Press.

Matthews, A., Garenne, M. (2013a). A dynamic model of the marriage market—Part 1: Matching algorithm based on age preference and availability. Theoretical Population Biology 88:78-85.

Matthews, A., Garenne, M. (2013b). A dynamic model of the marriage market—Part 2: Simulation of marital states and application to empirical data. Theoretical Population Biology 88:86-93.

Moen, Ph., Forest, K.B. (1999). Strengthening families: Policy issues for the twenty-first century. In: M.B. Sussman, S.K. Steinmetz, G.W. Peterson (Eds.), Handbook of marriage and the family $2^{\text {nd }}$ edition (pp. 633-663). New York: Plenum Press.

Muller, C., Gnanasekaran, K., Knapp, K. (1999). Housing and living arrangements for the elderly: an international comparison study. New York: International Longevity Center.

National Research Council - NRC (2000). Beyond six billion: Forecasting the world's population. Panel on Population Projections. J. Bongaarts, R. Bulatao (Eds.). Committee on Population, Commission on Behavioral and Social Sciences and Education. Washington DC: National Academy Press.

Nelissen, J. (1994). Income redistribution and social security: An application of microsimulation. London: Chapman and Hill.

Nelissen, J. (1995). The interaction of household and labour market modules in microsimulation models. In: E. van Imhoff, A. Kuijsten, P. Hooimeijer, L. van Wissen (Eds.), Household demography and household modeling (pp. 319-341). Plenum Press: New York. 
OECD (2011). Doing better for families. Paris: OECD Publishing.

Office for National Statistics - ONS (2009). 2006-based marital status and cohabitation projections for England and Wales. Population Trends 136:112-120.

Pollard, J. (1975). Modelling human populations for projection purposes - some of the problems and challenges. Australian Journal of Statistics 17, 63-76.

Prinz, C. (1995). Changing family structure and emancipatory pension policy: The case of Austria. In: J.-P. Gonnot, N. Keilman, C. Prinz (Eds.), Social security, household, and family dynamics in ageing societies (pp. 149-179). Dordrecht etc.: Kluwer Academic Publishers.

Prinz, C., Nilsson, Å, Sellerfors, H. (1995). Alternative options for living arrangement models: A sensitivity analysis. In: E. van Imhoff, A. Kuijsten, P. Hooimeijer, L. van Wissen (Eds.), Household demography and household modeling (pp. 227-250). Plenum Press: New York.

Raftery, A., Li, N., Ševčíková, H., Gerland, P., Heilig, G. (2012). Bayesian probabilistic population projections for all countries. Proceedings of the National Academy of Sciences 109(35): 13915-13921.

Schoen, R. (1981). The harmonic mean as the basis of a realistic two-sex marriage model.

Demography 18:201-16.

Schoen, R. (1988). Modeling Multigroup Populations. New York: Plenum.

Settles, B. (1999). The future of the families. In: M.B. Sussman, S.K. Steinmetz, G.W. Peterson (Eds.), Handbook of marriage and the family 2nd edition (pp. 143-175). New York: Plenum Press.

Ševčíková, H., Li, N., Kantorová, V., Gerland, P., Raftery, A. (2016). Age-Specific Mortality and Fertility Rates for Probabilistic Population Projections. In: R. Schoen (Ed.), Dynamic Demographic Analysis (pp. 285-310). Cham: Springer.

Smith, R.T. (1968). Family. I. Comparative Structure. In: D. Sills (Ed.), International Encyclopedia of the Social Sciences Vol. 5 (pp. 301-313). New York: McMillan and Free Press.

Tillman, K., Nam, C. (2008). Family structure outcomes of alternative family definitions. Population Research and Policy Review 27:367-384. DOI 10.1007/s11113-007-9067-0.

Todd, P.M., Billari, F.C. (2003). Population-wide marriage patterns produced by individual mate search heuristics. In: F.C. Billari, A. Prskawetz (eds.), Agent-based computational demography (pp. 117-137). Heidelberg: Physica Verlag.

Todd, P.M., Billari, F., Simao, J. (2005). Aggregate age-at-marriage patterns from individual matesearch heuristics. Demography 42(3):559-574.

Tuljapurkar, S., Li, N., Feldman, M. (1995). High sex ratios in China's future. Science 267: 874-876.

United Nations (1973). Methods of projecting households and families. New York: United Nations.

United Nations Economic Commission for Europe - UNECE (2015). Conference of European

Statisticians Recommendations for the 2020 Censuses of Population and Housing. New York and Geneva: United Nations. 
US National Resources Planning Committee (1938). The problems of a changing population. Washington DC: Government Printing Office.

Van de Kaa, D. (1987). Europe's second demographic transition. Population Bulletin 42: 1-59.

Van Imhoff, E. (1992). A general characterization of consistency algorithms in multidimensional demographic projection models. Population Studies 46(1), 159-169.

Van Imhoff, E., Keilman, N. (1991). LIPRO 2.0: An application of a dynamic demographic projection model to household structure in the Netherlands. Amsterdam, Berwyn, PA: Swets and Zeitlinger Publishers.

Van Imhoff, E., Kuijsten, A., Hooimeijer, P., van Wissen, L. (1995). Household demography and household modelling. New York: Plenum Press.

Van Imhoff, E. and W. Post (1998). Microsimulation methods for population projection. Population: An English Selection 10(1): 97-138.

Van Vliet, W., Huttman, E., Fava, S. (1985). Housing needs and policy approaches: Trends in thirteen countries. Durham: Duke University Press.

Verdon, M. (1998). Rethinking households. London: Routledge.

Willekens, F. (2009). Continuous-time microsimulation in longitudinal analysis. In: A. Zaidi, A. Harding, P. Williamson (Eds.), New frontiers in microsimulation modelling (pp. 413-436). Surrey: Ashgate Publishing Ltd.

Willekens, F. (2010). Family and household demography. In Zeng Yi (Ed.), Encyclopedia of life support systems Vol 2 Demography (pp. 86-112). Oxford: UNESCO in partnership with EOLSS Publishers.

Willekens, F. (2018). Demography and life choices. Demotrends February 5, 2018. URL https://demotrends.org/2018/02/05/demography-and-life-choices/ accessed on 12 February 2018.

Willekens, F., Van Imhoff, E. (2015). Formal demography of families and households. In: Wright, J. (Ed.), International encyclopedia of the social and behavioral sciences $2^{\text {nd }}$ edition, vol. 8 (pp. 725 730. Oxford: Elsevier.

Willekens, F., Bijak, J., Klabunde, A., Prskawetz, A. (2017). The science of choice: An introduction. Population Studies 71, Supplement 1, S1-S13.

Wilson, T. (2013). The sequential propensity household projection model. Demographic Research 28: 681-712.

Zeng, Y., Vaupel, J., Wang Z. (1997). A multi-dimensional model for projecting family households: With an illustrative application. Mathematical Population Studies 6(3): 187-216.

Zeng, Y., Vaupel, J., Wang Z. (1999). Household projection using conventional demographic data. Population and Development Review, Supplementary Issue: Frontiers of Population Forecasting. Vol. 24: 59-87.

Zeng, Y., Land, K., Wang, Z., Gu, D. (2007). U.S. family household momentum and dynamics: An extension and application of the ProFamy method. Population Research and Policy Review 25:1-41. 
Zinn, S. (2012). A mate-matching algorithm for continuous-time microsimulation models.

International Journal of Microsimulation 5(1): 31-51.

Zinn, S. (2017). Simulating synthetic life courses of individuals and couples, and mate matching. In: A. Grow, J. Van Bavel (Eds.), Agent-Based Modelling in population studies (pp. 113-157). Cham: Springer. 